\title{
Construction of Self-Learning Ability System during Potential Curriculum Exploitation of College English
}

\author{
Xuelian Wang \\ Wuhan International Trade University, Wuhan, 430000, China
}

Keywords: Self-Learning ability, Potential curriculum, College English.

\begin{abstract}
Potential curriculum refers to the educational practices and outcomes that are not clearly defined in the curriculum and plans of colleges, which is part of the regular and effective college education. The rational development and utilization of the potential curriculum can effectively improve the self-learning ability of students. This paper points out the forms of potential curriculum in college English, and gives the method of constructing the system of self-learning ability based on potential curriculum of college English to provide some references for relevant researchers.
\end{abstract}

\section{Introduction}

The informationization of social life and the globalization of economy make English more and more important. English, as one of the most important information carriers, has become the most widely used language in all fields of human life. In the educational development strategy, many countries regard English education as an important component of citizens' quality education, and put it in a prominent position. At present, English teaching relies mainly on English knowledge taught by teachers, supplemented by self-study. However, it serves as a useful supplement to the dominant curriculum and a major component of the curriculum. Potential courses are often neglected in English teaching. Latent curriculum refers to the synthesis of various non-classroom teaching factors on campus. According to the form of expression and the scope of existence, it can be divided into the physical form of the potential curriculum. It includes all kinds of education, teaching facilities and equipment, various shapes, styles and colors on the campus, roads, floors and so on. Potential courses at the spiritual level. It shows the ethos of school, the style of teaching, the style of study, the idea of running a school, the atmosphere of campus culture, and the various management systems, such as its soul and foundation. Potential courses at the relational level. It shows the relationship between people in the campus, including the relationship between managers and teachers, students, the relationship between teachers and students, the relationship between students and students, the relationship between teachers and teachers, and so on. The potential curriculum has the characteristics of integrity and universality. Potential courses are not explicitly stated in the educational theories or principles of institutions, nor in the teaching programmers of institutions of higher learning. Through the non-compulsory effect of the school environment, it enables students to consciously participate in the environment without ideological burden and no mental pressure, so as to promote the cultivation of students' self-learning ability.

\section{Potential Curriculum Forms of College English}

Potential Curriculum of Teaching Activities. College English Teaching in the language knowledge, but also covers the English-speaking countries of geographical conditions, economic, political, historical culture and local customs and practices, let the students have a better perception of western culture in the process of learning, to cultivate their intercultural communicative competence, which reflects the hidden curriculum. Teaching activities in teaching the class as a unit, the teacher imparting knowledge according to certain teaching ideas, ability training, the organization, 
the selection and use of teaching methods, teacher-student relationship, teaching effect evaluation contains many influencing factors of education, imperceptibly affect students' mind. During language practice, students unconsciously accepted the implications of education, which brought about some unexpected learning experiences. The rapid development of modern information technology provides abundant resources for college students to learn English, in addition to the traditional textbooks, learning counseling books, magazines, radio and television, video recording, software and network information resources are English learning a good helper. There are rich moral and cultural thoughts in these resources, and the latent curriculum needs to be fully excavated and refined by teachers, so that students need to absorb them fully and selectively. College English course is a course of language acquisition, which is different from other courses. It requires students to practice often, repeatedly, and plenty of practice. A single classroom teaching activity is not enough to arouse the enthusiasm of students, and there should be a variety of extra-curricular teaching activities as a supplement to attract the attention of students and improve their enthusiasm for participation. Design and carry out various forms, interesting, and participate in a wide range of extra-curricular activities, students have good help in English learning.

Potential Curriculum of Teaching Environment. Teaching environment not only refers to the classroom environment, but also includes school buildings, campus culture, classroom atmosphere, teaching facilities and classroom design. These are the material factors of the potential curriculum, and play a certain role in guiding and stimulating students' learning. University campus is not only a place for imparting knowledge and skills, but also a place to show humanistic spirit and a place for edifying sentiments. Environmental factors in College English teaching can stimulate students' initiative and enthusiasm, stimulate students' imagination and creativity, while the teaching environment is mainly constructed by potential courses. Any kind of teaching activities must be carried out in a certain environment, and the teaching of college English should be based on the school, classroom and other material media. The significance of potential courses for college English learning has not yet been extensively exploited and utilized. Since language learning requires a wide range of language environments, explicit courses cannot meet this requirement at any rate. At the same time, the latent curriculum, which is opposite to the explicit curriculum, shows its important influence on language learning. As an important achievement of curriculum theory research, potential curriculum is also exerting its potential value, and has positive effect on English teaching and learning. English, as a second language for college students, often needs the help of the external environment to acquire it. If the foreign language teaching building architectural design school is the main English speaking countries of the architectural style of English cultural intimacy may be so however each student approached the teaching building, their learning attitude may become more active. Another example in the teaching building, between teachers and students, between students and students with English greeting, communication, real context to enhance classroom teaching, organize students to classroom activities related to the second, this can stimulate students to strengthen oral English training and English proficiency training. Each element contains a wealth of potential curriculum content. These different levels of college English potential curriculum play a prominent role in promoting students' English learning and enhancing their self-learning ability.

Potential Curriculum of Interpersonal Relationship. The cultivation of college Students' communicative competence is achieved through constant communication with teachers and students. Therefore, in foreign language classroom teaching, teachers should make efforts to change the way of interpersonal communication, strengthen communication with students, and provide more opportunities for students to communicate with each other. Emphasis on cooperative learning in the classroom, such as classroom discussions, group learning, and so on, to establish a student interaction centered classroom teaching model, to create more convenient conditions for students to communicate with each other. At the same time, the relationship between teachers and students is the most important part of the university of interpersonal relationship, only in a harmonious and harmonious relationship between teachers and students, students will close its teacher, the teacher, will move in the desired direction, will have a complementary effect of the Teaching benefits teachers as well as students. The establishment of a good and harmonious interpersonal relationship between 
teachers and students and between students and students is a prerequisite for the implementation of quality education. Harmonious teacher-student relationship is a new teacher-student relationship of democracy and equality, respect and love, emotional integration, the cooperation established between teachers and students. First, teachers should be devoted to their students. Secondly, teachers should carry out teaching democracy. Teaching must be geared to all students, considering the needs of all students, and not being partial to certain students or students. Students should be encouraged to express their opinions and not express their dissatisfaction or deny them easily. Teachers should actively adopt encouraging evaluation, and be good at maintaining their self-esteem and enthusiasm for study. Teachers should guide students to form good relationship with classmates. A harmonious relationship between students and students means that students can help each other, work together and respect each other. Such a good and positive interpersonal relationship is good for students' physical and mental health, and helps students improve their self-study ability.

\section{Construction of Self-Learning Ability System during Potential Curriculum Exploitation}

Cultivate Preview Habit before the Hidden Class. Preparation is an effective means for students to acquire knowledge independently. The materials used to focus on the cultivation of English reading ability as the goal of English teaching, the preview is important way of cultivating students' English reading methods under the guidance of teachers, is the first step in developing their reading ability. So start self-study guidance, students should be asked in each lesson carefully before you preview, require the use of vocabulary, spelling words in the text, understand every word pronunciation, form and meaning. Use the text notes to understand the tenor of the text sentence by sentence. The grammatical structure of long and difficult sentences in the text is preliminarily clarified. Write down the grammar that you can't understand and understand in the preview. Such as requiring students to use self-study ability to preview before class, in the potential classroom teaching can be twice the result with half the effort, to improve classroom efficiency. In the first year of college, students are required to preview, which can fundamentally cultivate students' ability to study independently, and enable them to master knowledge well and promote their intellectual development. Through the cultivation of memory ability and good habits before class, teachers should guide students to improve self-learning ability constantly, which requires teachers to guide students to increase extracurricular reading. Institutions of higher learning have a certain time to study, let students' self-study, in order to prepare new lessons, digestion, consolidate the knowledge, improve ability. However, many of our current students are not good at or unwilling to take advantage of these time to study, wasted in learning valuable time. A few years later, even though I was a classmate, I was equally qualified to enter colleges. Potential courses can greatly improve the students' Preview ability, so that many students can improve their academic records.

Cultivate Exploration Habit during the Hidden Class. Active classroom environment can stimulate and maintain students' interest in exploration, and promote students' Autonomous learning. The creation of the classroom environment here is not only a physical environment for students to learn, but more importantly, to create a learning atmosphere suitable for students to study autonomously. Although students' learning environment is an external factor affecting students' learning, it can stimulate students' learning motivation, and teachers' positive attitude towards students can effectively improve their learning motivation and academic achievement. The active classroom environment can help students to be interested in the whole learning process and participate in the learning process actively, which is an important characteristic of self-regulated learning. The teacher consciously digs and trains the students' interests and tries to make them interesting. The second classroom refers to the environment and instruction for students to practice language after class. Such as the establishment of campus English radio, in a news broadcast, English poetry, dialogue, cultural stories and learning as the broadcast content, teachers recommend or provide classic foreign movies for students to play English movies, feelings of language and culture in the actual environment, promote the establishment of language environment, foreign language competition held, such as speech and debate become, writing, vocabulary contest and other activities, 
provide some challenging tasks, motivate students' interest in learning, to promote students' ability to use English. These are important forms of potential courses. Finally, we should cultivate the positive feelings between teachers and students to arouse students' enthusiasm for learning English. Enthusiasm has a great influence on language learning and has a positive impact on foreign language learning. One of the teacher's important responsibilities is to help students develop an interest in learning. In English teaching, teachers can give full play to the vivid features of English courses, so as to attract and stimulate the students' strong desire to learn English by themselves.

Cultivate Reflection Habit after the Hidden Class. Potential curriculum is an important means to cultivate college students' habit of reflection. To ensure the effectiveness of autonomous learning, teachers should monitor the learner's learning process, the implementation of learning plans, and the use and development of learning skills. It is one of the most important means to train learners to evaluate themselves and evaluate each other. Self-assessment, to evaluate the effectiveness of autonomous learning, is necessary for learners. It can help learners build self-confidence, test learning effects and enhance learning motivation. In addition, teachers can also learn about their learning through questionnaires, online communication and interviews. Learner assessment to each other is an important part of cultivating autonomous learning ability is indispensable to learners, learners can learn from each other, mutual gaps. Teachers in monitoring at the same time, the students' autonomous learning situation timely feedback, provide valuable guidance, so that students are not only study, but also learn something, really improve the ability of autonomous learning with the teacher as the guide, students as the main body of the students. The cultivation of autonomous learning ability depends not only on the learner's awareness of the importance of autonomous learning, but also on the cultivation of autonomous learning strategies. In the process of English teaching, teachers should respect learners' individual differences, combine strategy guidance and training with routine teaching activities, and enable students to develop autonomous learning habits imperceptibly. In our current educational environment to cultivate students' autonomous learning ability, break with the old teaching mode and the old habit of learning, improve the teaching system, teaching environment, there is a long way to go. As long as we consciously develop the learner's autonomous language learning ability in the potential curriculum, we will be getting closer and closer to the ultimate goal of complete autonomy.

\section{Conclusion}

There are many potential curriculum factors in English classroom teaching. Teachers should realize the importance of potential curriculum for college English learning and give full play to the role of potential curriculum in college English teaching. The development of potential courses in College English should be combined with the actual situation of schools to tap the value of potential courses and enhance their self-learning ability before, after, and after the potential courses.

\section{References}

[1] Yu Boying, Shi Guangxiao. A Reexamination of Hidden Curriculum [J]. Technology Enhanced Foreign Language Education, 2012(1): 57-62.

[2] Wu Xuan. The Potential Values of Hidden Curriculum in English Teaching [J]. Journal of Heilongjiang College of Education, 2011, 30(3): 159-160.

[3] Pu Yinghui. The Research on Ethic Recognition of Minority English Education on the Intervention of Potential Courses [J]. Guizhou Ethnic Studies, 2015, 36(3): 206-209.

[4] Hu Pingping. A Case Study of Teacher's Hidden Agenda in College English Teaching [J]. Technology Enhanced Foreign Language Education, 2016(4): 20-25+31. 